\title{
Huge central intravascular papillary endothelial hyperplasia of the mandible: a case report and review of the literature
}

\author{
Hassan Mirmohammadsadeghi', Fatemeh Mashhadiabbas ${ }^{2}$, Fatemeh Latifi' \\ Departments of ${ }^{1}$ Oral and Maxillofacial Surgery and ${ }^{2}$ Oral and Maxillofacial Pathology, Dental School, \\ Shahid Beheshti University of Medical Sciences, Tehran, Iran
}

\begin{abstract}
J Korean Assoc Oral Maxillofac Surg 2019;45:180-185)
Masson's tumor or intravascular papillary endothelial hyperplasia is an inflammatory soft tissue lesion that rarely occurs in the maxillofacial region and skeletal system. Precise clinical and para-clinical investigation is necessary for the accurate diagnosis and correct treatment of this lesion. This paper presents a massive intravascular papillary endothelial hyperplasia lesion in the bony tissue of the mandible. Histopathology features, clinical appearance, and suitable management are discussed, with a complete review of the literature. The patient underwent composite resection of the lesion as well as reconstruction. No recurrence was observed during 6 years of follow-up. To the best of our knowledge, this is the fourth case of Masson's tumor in mandibular skeletal tissue, which has unique and distinctive features due to its size and location. A rare occurrence in skeletal tissue, complex clinical presentations, and complicated histopathologic findings present diagnostic challenges for treatment of this lesion.
\end{abstract}

Key words: Intravascular papillary endothelial hyperplasia, Histopathology, Mandible, Bone

[paper submitted 2018. 10. 22 / revised 2018. 11. 27 / accepted 2018. 12. 20]

\section{Introduction}

Intravascular papillary endothelial hyperplasia (IPEH) was first described in 1923 by Masson ${ }^{1}$ as hemangioendotheliome vegetant intravasculaire. It is a benign vascular lesion that predominantly occurs in the skin and subcutaneous tissue of the trunk, fingers, and head and neck regions. Oral IPEH lesions are uncommon and a review of oral lesions conducted in 2004 reported only 91 cases of the oral mucosa and lips².

IPEH is an inflammatory vascular lesion with a trauma etiology and nonspecific clinical characteristics. Due to the complex presentation, it should be differentiated from other soft tissue tumors, especially angiosarcoma.

\footnotetext{
Fatemeh Latifi

Department of Oral and Maxillofacial Surgery, Dental School, Shahid Beheshti University of Medical Sciences, Velenjak St., Shahid Chamran Highway, Tehran 1985717443, Iran

TEL: +98-9123236333 FAX: +98-2122643126

E-mail:dr.flatifi@gmail.com

ORCID: https://orcid.org/0000-0002-7326-0247

(c) This is an open-access article distributed under the terms of the Creative Commons Attribution Non-Commercial License (http://creativecommons.org/ licenses/by-nc/4.0/), which permits unrestricted non-commercial use, distribution, and reproduction in any medium, provided the original work is properly cited.

Copyright (C) 2019 The Korean Association of Oral and Maxillofacial Surgeons. All rights reserved.
}

According to the literature, only three cases of IPEH in the maxillofacial skeletal tissues have been reported previously $^{3-5}$.(Table 1) This article describes a case of pure IPEH involving half of the mandible. The lesion mimicked a malignant tumor and because of the uncommon location, huge size, and complicated histology, representing a considerable diagnostic challenge.

\section{Case Report}

A 45-year-old male was referred to the Department of Oral and Maxillofacial Surgery of Taleghani Hospital (Shahid Beheshti University of Medical Sciences, Tehran, Iran) in 2011, with a chief complaint of a huge malodorous mass in the mouth. Five years ago, during dental visit, the patient first noticed a small prominent lesion on the left side of mandible. The patient did not seek treatment and the lesion gradually progressed to a large destructive mass. The mass grew suddenly and considerably in the past two months. Extraoral examination revealed obvious facial asymmetry due to bulging of the left side of face from the buccal to the submandibular region.(Fig. 1) The skin was intact without any sloughing or color change. The patient suffered from paresthesia of the left infraalveolar nerve and severe halitosis. Intraoral examination 
Table 1. Reports of intravascular papillary endothelial hyperplasia in maxillofacial skeletal tissue

\begin{tabular}{|c|c|c|c|c|c|}
\hline Study & $\begin{array}{l}\text { Age }(y r) / \\
\text { sex }\end{array}$ & Location & Chief complain & Clinical appearance & Radiographic finding \\
\hline $\begin{array}{l}\text { Komori et al. } \\
\text { (1984) }\end{array}$ & $49 / \mathrm{F}$ & $\begin{array}{l}\text { Right mandibular body; from the } \\
\# 44 \text { to \#47 tooth region }\end{array}$ & - & $\begin{array}{l}\text { Normal covering } \\
\text { mucosa }\end{array}$ & Multilocular radiolucency \\
\hline $\begin{array}{l}\mathrm{Xu} \text { and } \mathrm{Li}^{4} \\
(2014)\end{array}$ & $14 / \mathrm{M}$ & $\begin{array}{l}\text { Right ramus of mandible; } \\
5 \times 5 \times 6 \mathrm{~cm} \text { involved buccal } \\
\text { space and extended } \\
\text { into infratemporal fossa }\end{array}$ & $\begin{array}{l}\text { Facial swelling } \\
\text { and trismus }\end{array}$ & $\begin{array}{l}\text { Firm, painful, fixed } \\
\text { mass }\end{array}$ & $\begin{array}{l}\text { Multilocular, expansile, } \\
\text { well-circumscribed, osteolytic } \\
\text { lesion with cortex destruction }\end{array}$ \\
\hline $\begin{array}{l}\text { Tanio et al. } \\
\text { (2016) }\end{array}$ & $75 / \mathrm{M}$ & $\begin{array}{l}\text { Anterior mandible; from the } \\
\# 32 \text { to \#44 tooth region }\end{array}$ & $\begin{array}{l}\text { Pain on the } \\
\text { left side of the } \\
\text { mandible }\end{array}$ & $\begin{array}{l}\text { Bony hard swelling, } \\
\text { normal mucosa, } \\
\text { persistent bleeding } \\
\text { at biopsy }\end{array}$ & $\begin{array}{l}\text { Multilocular radiolucent lesion } \\
\text { with cortical bones destruction }\end{array}$ \\
\hline Our case & $45 / \mathrm{M}$ & $\begin{array}{l}\text { Left side of mandible; from tooth } \\
\# 32 \text { to the left mandibular ramus } \\
\text { with vertical extension to the } \\
\text { maxillary vestibule and sub lingual } \\
\text { and sub mandibular region }\end{array}$ & $\begin{array}{l}\text { Huge malodorous } \\
\text { mass }\end{array}$ & $\begin{array}{l}\text { Enlarged ulcerative } \\
\text { mass with necrotic } \\
\text { appearance, easy } \\
\text { bleeding, facial } \\
\text { asymmetry }\end{array}$ & $\begin{array}{l}\text { Massive multilocular osteolytic } \\
\text { lesion with bony expansion and } \\
\text { cortex destruction }\end{array}$ \\
\hline
\end{tabular}

(F: female, M: male)

Hassan Mirmohammadsadeghi et al: Huge central intravascular papillary endothelial hyperplasia of the mandible: a case report and review of the literature. J Korean Assoc Oral Maxillofac Surg 2019

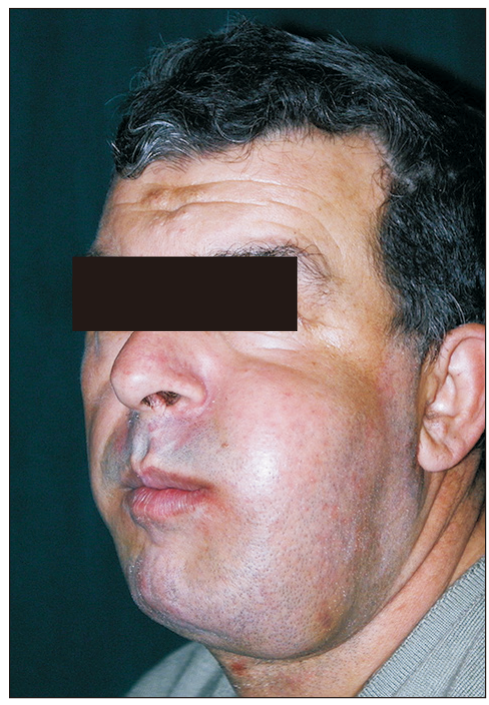

Fig. 1. Extraoral appearance of the lesion.

Hassan Mirmohammadsadeghi et al: Huge central intravascular papillary endothelial hyperplasia of the mandible: a case report and review of the literature. J Korean Assoc Oral Maxillofac Surg 2019

revealed a huge, expansile lesion from tooth \#32 to the left mandibular ramus, which caused tooth displacement. Vertical extension to the maxillary vestibule and sublingual region was evident. The bulky lesion displaced the tongue and interfered with mouth movement. The lesion was covered by ulcerative and necrotic tissue.(Fig. 2) The patient reported easy bleeding of the lesion, which was spontaneous or caused by minor trauma. Due to its dark appearance, the first clinical diagnosis by the Department of Oral Medicine was melanoma. Panoramic radiography and computed tomography revealed an extended multilocular osteolytic lesion with bony

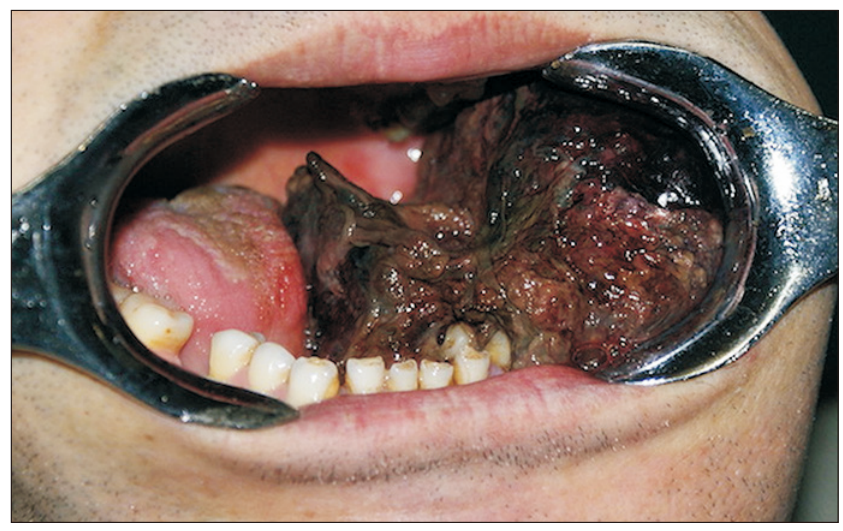

Fig. 2. Intraoral appearance of the lesion.

Hassan Mirmohammadsadeghi et al: Huge central intravascular papillary endothelial hyperplasia of the mandible: a case report and review of the literature. J Korean Assoc Oral Maxillofac Surg 2019

expansion and cortical destruction. There was obvious tooth displacement and root resorption.(Fig. 3, 4)

Based on the clinical and radiographic examinations, the differential diagnosis focused on malignant bony tumors including intraosseous odontogenic carcinoma, clear cell odontogenic carcinoma, ameloblastic fibrosarcoma, and osteosarcoma.

Incisional biopsy was performed and histologic sections showed a necrotic lesion with mixed inflammatory cells and fungal hyphae, likely Mucorales.

Because pathology confirmed a diagnosis of mucormycosis, the patient underwent left hemimandibulectomy with bone and soft tissue resection (Fig. 5) and reconstruction with a reconstruction plate and a pectoralis major myocutaneous pedicled flap. Definitive histopathologic examination of the 

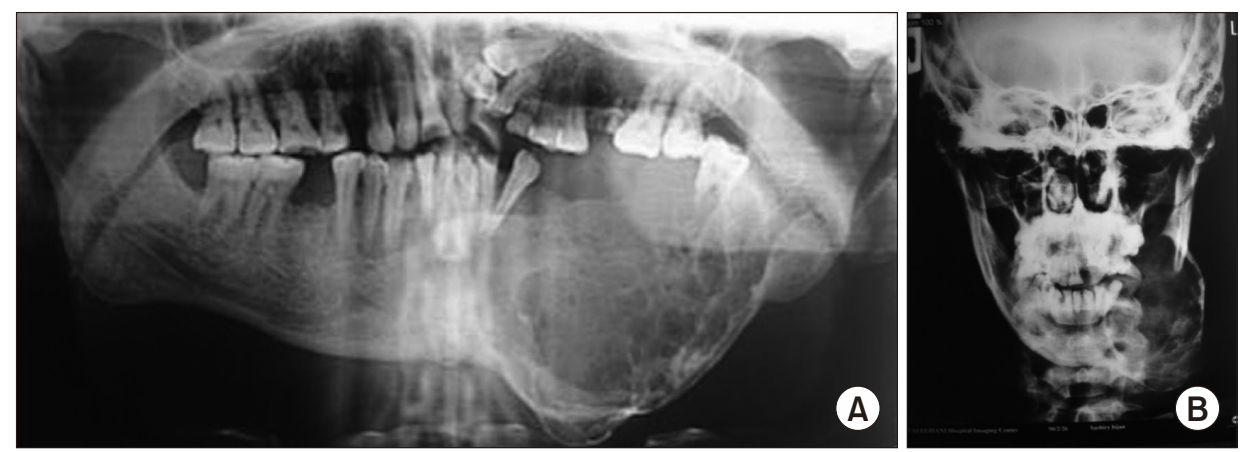

Fig. 3. Extraoral radiography of the lesion. A. Panoramic view. B. Posteroanterior mandible view.

Hassan Mirmohammadsadeghi et al: Huge central intravascular papillary endothelial hyperplasia of the mandible: a case report and review of the literature. $J$ Korean Assoc Oral Maxillofac Surg 2019
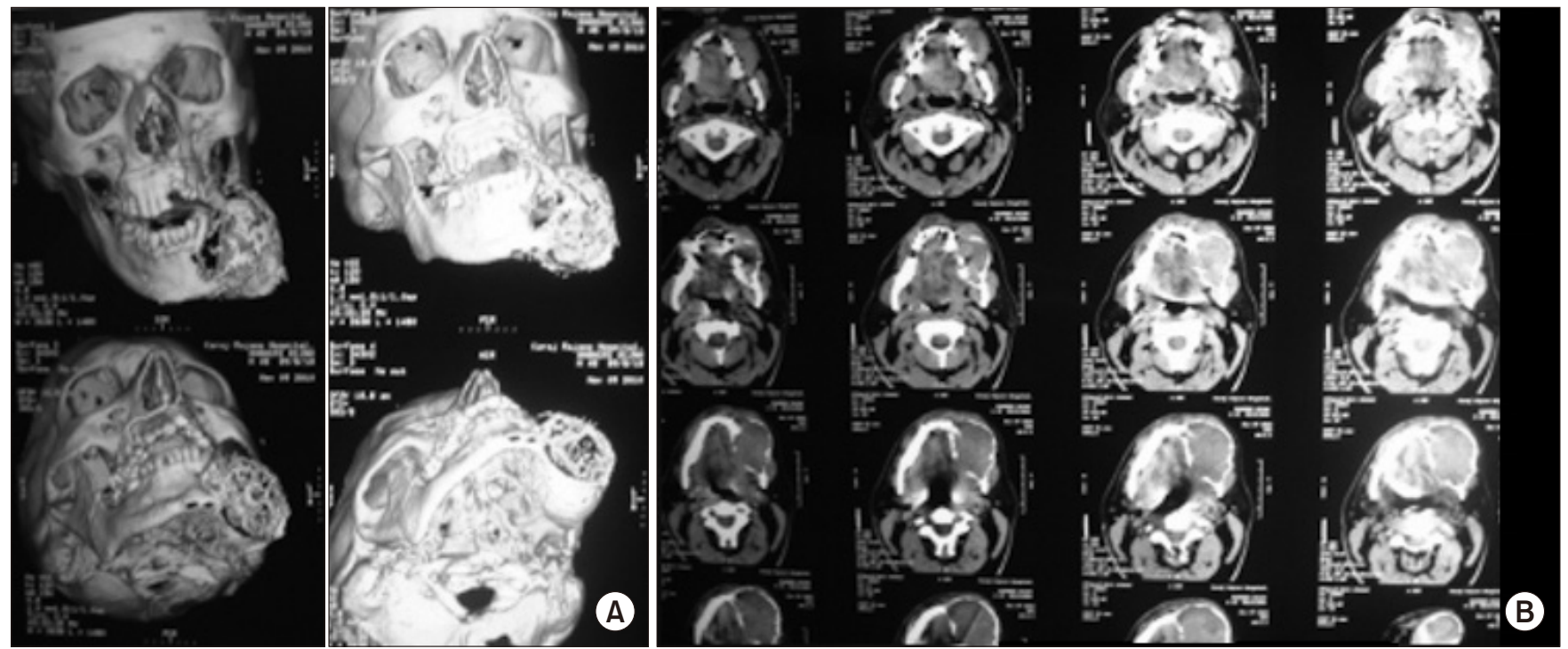

Fig. 4. Computed tomography of the lesion. A. Three-dimensional view. B. Axial view.

Hassan Mirmohammadsadeghi et al: Huge central intravascular papillary endothelial hyperplasia of the mandible: a case report and review of the literature. J Korean Assoc Oral Maxillofac Surg 2019

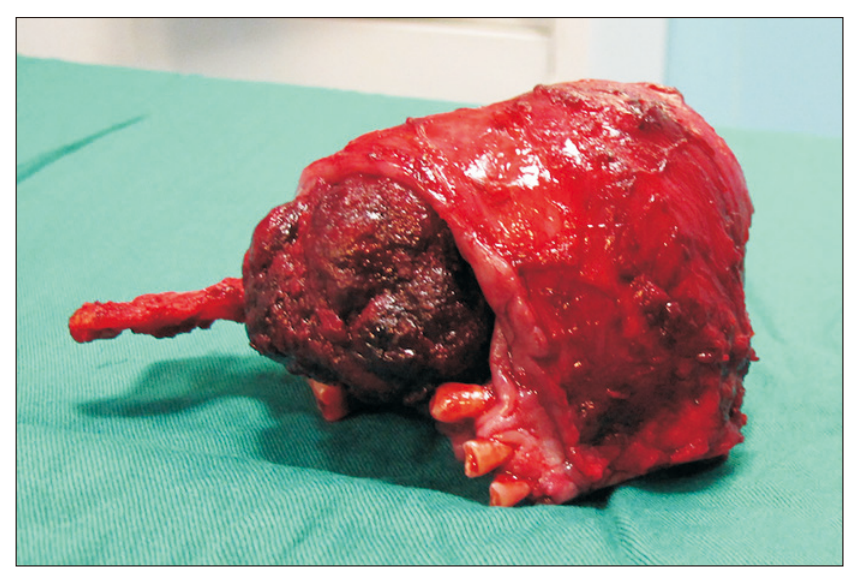

Fig. 5. Resected specimen.

Hassan Mirmohammadsadeghi et al: Huge central intravascular papillary endothelial hyperplasia of the mandible: a case report and review of the literature. J Korean Assoc Oral Maxillofac Surg 2019

resected specimen confirmed a vascular tumor characterized by numerous papillae formation in the vessels. The papillae were covered by one to two layers of endothelial cells and encompassed a hyalinized fibrous tissue core. The vascular lumen was dilated with thrombosis and many hemorrhages. (Fig. 6) Surgical margins showed inflamed granulation tissue with cholesterol clefts and reactive bone formation. The intraoral part of the tumor was covered by an ulcerated epithelium with a fibrinopurulent membrane in some areas. There was no evidence of malignancy. The lesion was finally diagnosed as pure-type IPEH. The postoperative course was uneventful and there was no recurrence during seven years of follow-up.

\section{Discussion}

IPEH is a rare vascular lesion of the skin and subcutaneous tissue and can be distinguished by multiple papillary processes and proliferation of endothelial cells ${ }^{6}$.

Masson first described this lesion as a form of endothelial cell neoplasm causing subsequent vascular obstruction and 

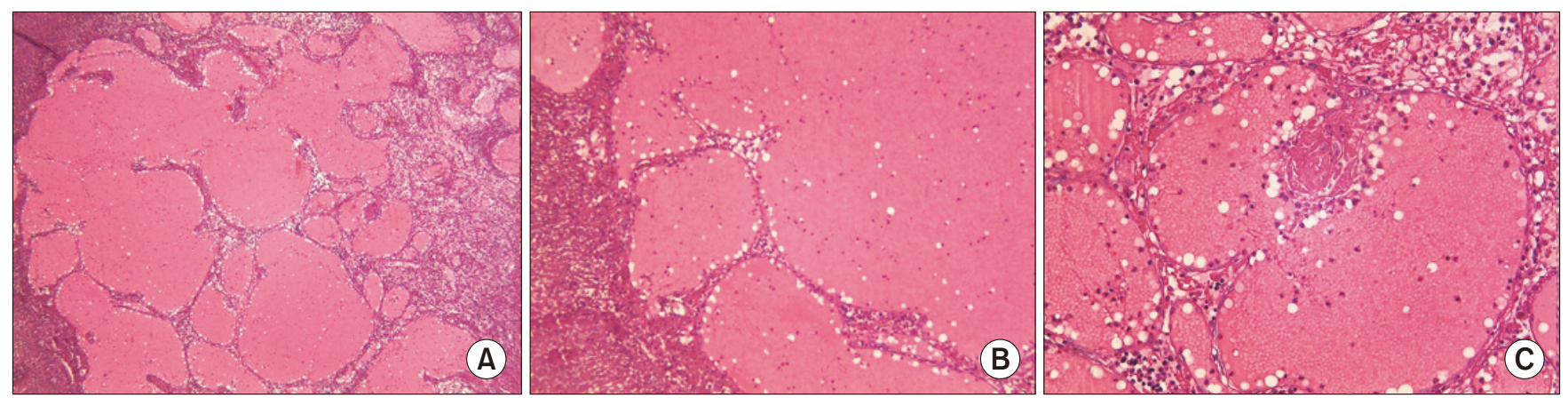

Fig. 6. Histologic section (H\&E staining). A. Papillary endothelial cell proliferation in the dilated vascular lumen ( $\times 40)$. B. Papillae lined by plump endothelial cells (x100). C. Papillae with a vascular core lined by active endothelial cells (×200).

Hassan Mirmohammadsadeghi et al: Huge central intravascular papillary endothelial hyperplasia of the mandible: a case report and review of the literature. $J$ Korean Assoc Oral Maxillofac Surg 2019

tissue necrosis ${ }^{7}$. Other investigators focused on the reactive process of the lesion following thrombus organization and endothelization ${ }^{8}$. Hyperemia or lymph stasis and local production of angiogenic growth factors are another suggested pathogenesis of this lesion. Expression of Ki-67 during active phases of the cell cycle suggest a neoplastic source of the lesion', but due to granulation tissue formation, a reactive etiology of endothelial cell proliferation is the most likely pathogenesis of $\mathrm{IPEH}^{10}$. Most prior studies cited hormonal impacts and the female predilection of the lesion ${ }^{11}$. IPEH is more common in older patients and the most common regions are the head and neck (23\%), lower extremities (17\%), and fingers $(16 \%)^{12}$. It rarely occurs in the oral cavity and most intraoral sites are the lower lip followed by the tongue, buccal mucosa, and upper lip ${ }^{13}$.

In 1983, Hashimoto et al. ${ }^{14}$ described three subtypes of IPEH: (1) pure, developing in the dilated vessels of the figure and head-neck region; (2) mixed, forming over a preexisting lesion like a hemangioma, artero-vascular malformation, pyogenic granulomatosis, aneurysm, or chronic disease with venous thrombosis; or (3) extravascular, originating from previous hematoma with a history of trauma.

Similar to the common occurrence of phleboliths in vascular lesions, numerous microcalcifications may be seen in IPEH that cause vascular occlusion and tissue necrosis. Because of the diverse presentations of this lesion, computed tomography with contrast media or magnetic resonance imaging reveals the vascularity and extent of lesion, but have limited usefulness in differential diagnosis ${ }^{15}$.

Clinical manifestations of the lesion are not specific and it is difficult to differentiate from other neoplasms or vascular lesions. Thus, according to location and size, IPEH may mimic different lesions such as mucoceles, hemangiomas, hematomas, intravenous pyogenic granulomas, phlebectasias, salivary gland tumors, nevi, Kaposi's sarcomas, or angiosarcomas.

Angiosarcoma is the most important malignant lesion to differentiate from IPEH. Areas of organized thrombus in the dilated vessels and proliferation of endothelial cells in papillary form toward the lumen are important for diagnosis of IPEH. The circumscribed and intravascular location of the lesion and presence of thrombotic material, along with absence of nuclear hyperchromia, cellular pleomorphism, atypical mitosis, foci of necrosis, and irregular capillary vessels are also major features differentiating IPEH from angiosarcoma ${ }^{16}$.

Complete excision with healthy margins is the accepted treatment plan. Cohen et al. ${ }^{17}$ used sclerotherapy with sodium tetradecyl sulfate prior to resection with the aim of minimizing bleeding and improving esthetic results in one case of mixed IPEH of lip. Other treatment methods like endoscopic surgery and use of beta-adrenergic antagonists were reported according to the site involved ${ }^{18}$. In the case of multiple intracranial lesions or anatomic limitations that could result in incomplete resection, adjuvant radiotherapy or chemotherapy have been associated with a good prognosis ${ }^{19}$.

Although recurrence of the IPEH is rare, incomplete resection or recurrence of the primary vascular lesion are possible causes. Furthermore, in the case of recurrent IPEH, thorough investigation to rule out angiosarcoma is needed.

The case reported here is notable because of some particularities: First it is the fourth reported case of IPEH in the mandible. Since the first mandibular lesion was reported in $1984^{3}, \mathrm{Xu}$ and $\mathrm{Li}^{4}$ reported one case of IPEH at the mandibular ramus with expansile and osteolytic characteristics in 2014. The lesion appeared with swelling and trismus and was initially thought to be a case of fibrous dysplasia, ameloblas- 
toma, and giant cell tumor. In 2016, Tanio et al. ${ }^{5}$ reported a mixed IPEH associated with hemangioma of the anterior segment of the mandible, in which embolization of the inferior alveolar artery was performed followed by successful removal. None of the reported lesions were as large or as long-term as this case, with significant intraoral and extraoral extension. The large size of this lesion and subsequent local circulation disorder resulted in tissue necrosis and fungal infection, leading to the diagnostic challenge and variation in pathologic results encountered in this case.

According to the literature, not only are mandibular IPEH lesions rare, but the occurrence of IPEH in skeletal tissue is also uncommon ${ }^{13}$. Jain et al. ${ }^{20}$ reported one case of IPEH in the hard palate masquerading as adenoid cystic carcinoma.

Resection of multiple recurrent IPEHs affecting the skin and tibia in a 75-year-old male over the course of three years was reported by Higashi et al. ${ }^{21}$ in 2009. The patient had hepatitis $\mathrm{C}$, hepatoma, and associated coagulopathy and it was suggested that liver dysfunction and induced microthrombus formation were the probable etiology.

The spine, skull, and skull base are other skeletal sites involved in IPEH that have been reported in the literature ${ }^{22-25}$.

In conclusion, IPEH as an inflammatory vascular soft tissue lesion may occur in hard tissue of the head and neck region, without a history of trauma. Tissue necrosis and mixed infection are the result of circulation disruption. Differentiating this lesion from malignant vascular tumors like angiosarcoma is an important and challenging task for oral and maxillofacial pathologists and surgeons.

\section{ORCID}

Hassan Mirmohammadsadeghi, https://orcid.org/00000002-3132-2489

Fatemeh Mashhadiabbas, https://orcid.org/0000-00033789-1727

Fatemeh Latifi, https://orcid.org/0000-0002-7326-0247

\section{Authors' Contributions}

H.M. and F.M. participated in study design and coordination and helped to draft the manuscript. F.L. participated in the study design, data collection and wrote the manuscript. All authors read and approved the final manuscript.

\section{Consent for Publishing Photographs}

Written informed consent was obtained from the patients for publication of this article and accompanying images.

\section{Conflict of Interest}

No potential conflict of interest relevant to this article was reported.

\section{References}

1. Masson P. Hemangioendotheliome vegetant intravasculaire. Bull Soc Anat (Paris) 1923;93:517-23.

2. Makos CP, Nikolaidou AJ. Intravascular papillary endothelial hyperplasia (Masson's tumor) of the oral mucosa. Presentation of two cases and review. Oral Oncol Extra 2004;40:59-62.

3. Komori A, Koike M, Kinjo T, Azuma T, Yoshinari M, Inaba H, et al. Central intravascular papillary endothelial hyperplasia of the mandible. Virchows Arch A Pathol Anat Histopathol 1984;403:4539.

4. Xu SS, Li D. Radiological imaging of florid intravascular papillary endothelial hyperplasia in the mandibule: case report and literature review. Clin Imaging 2014;38:364-6.

5. Tanio S, Okamoto A, Majbauddin A, Sonoda M, Kodani I, Doi $\mathrm{R}$, et al. Intravascular papillary endothelial hyperplasia associated with hemangioma of the mandible: a rare case report. J Oral Maxillofac Surg Med Pathol 2016;28:55-60.

6. Mahapatra QS, Sahai K, Malik A, Mani NS. Intravascular papillary endothelial hyperplasia: an unusual histopathological entity. Indian Dermatol Online J 2015;6:277-9.

7. Tarallo M, Spagnoli AM, Fino P, Lo Torto F, Scuderi N. Masson's tumor: a soft tissue tumor simulating a tendon cyst: case report. $\mathrm{G}$ Chir 2012;33:34-7.

8. Kim D, Israel H, Friedman M, Kuhel W, Langevin CJ, Plansky T. Intravascular papillary endothelial hyperplasia manifesting as a submandibular mass: an unusual presentation in an uncommon location. J Oral Maxillofac Surg 2007;65:786-90.

9. Bologna-Molina R, Amezcua-Rosas G, Guardado-Luevanos I, Mendoza-Roaf PL, González-Montemayor T, Molina-Frechero N. Intravascular papillary endothelial hyperplasia (Masson's tumor) of the mouth - a case report. Case Rep Dermatol 2010;2:22-6.

10. Korkolis DP, Papaevangelou M, Koulaxouzidis G, Zirganos N, Psichogiou H, Vassilopoulos PP. Intravascular papillary endothelial hyperplasia (Masson's hemangioma) presenting as a soft-tissue sarcoma. Anticancer Res 2005;25:1409-12.

11. Pins MR, Rosenthal DI, Springfield DS, Rosenberg AE. Florid extravascular papillary endothelial hyperplasia (Masson's pseudoangiosarcoma) presenting as a soft-tissue sarcoma. Arch Pathol Lab Med 1993;117:259-63.

12. Liu DT, Shields CL, Tse GM, Lam DS. Periocular papillary endothelial hyperplasia (Masson's tumour) in Behçet's disease. Acta Ophthalmol 2012;90:e413-5.

13. Sarode GS, Sarode SC, Karmarkar SP. Oral intravascular papillary endothelial hyperplasia (Masson's tumor): a review of literature. J Oral Maxillofac Surg Med Pathol 2014;26:73-9.

14. Hashimoto H, Daimaru Y, Enjoji M. Intravascular papillary endothelial hyperplasia. A clinicopathologic study of 91 cases. Am J Dermatopathol 1983;5:539-46.

15. Ginat DT, Walcott BP, Mordes D, Schaefer PW, Nahed B. Intracranial organizing hematoma with papillary endothelial hyperplasia features after resection and involved field radiotherapy for cerebel- 
lar juvenile pilocytic astrocytoma. Clin Imaging 2014;38:322-5.

16. Fomete B, Samaila M, Edaigbini S, Agbara R, Okeke UA. Primary oral soft tissue angiosarcoma of the cheek: a case report and literature review. J Korean Assoc Oral Maxillofac Surg 2015;41:273-7.

17. Cohen A, Maly A, Azaz B. Intravascular papillary endothelial hyperplasia of the lower lip: surgical approach and review of the literature. Gerodontology 2009;26:305-8.

18. Wang ZH, Hsin CH, Chen SY, Lo CY, Cheng PW. Sinonasal intravascular papillary endothelial hyperplasia successfully treated by endoscopic excision: a case report and review of the literature. Auris Nasus Larynx 2009;36:363-6.

19. Shih CS, Burgett R, Bonnin J, Boaz J, Ho CY. Intracranial Masson tumor: case report and literature review. J Neurooncol 2012;108:211-7.

20. Jain S, Khurana N, Gulati A. Intravascular papillary endothelial hyperplasia of the palate masquerading as adenoid cystic carcinoma on fine needle aspiration cytology: a potential diagnostic pitfall. Cytopathology 2012;23:198-200.

21. Higashi Y, Uchida Y, Yoshii N, Kubo H, Kanzaki T, Yokouchi M, et al. Multiple intravascular papillary endothelial hyperplasia affecting skin and bone. Clin Exp Dermatol 2009;34:e740-3.

22. Petry M, Brown MA, Hesselink JR, Imbesi SG. Multifocal intra- vascular papillary endothelial hyperplasia in the retroperitoneum and spine: a case report and review of the literature. J Magn Reson Imaging 2009;29:957-61.

23. Lee SK, Jung TY, Baek HJ, Kim SK. Destructive radiologic development of intravascular papillary endothelial hyperplasia on skull bone. J Korean Neurosurg Soc 2012;52:48-51.

24. Park KK, Won YS, Yang JY, Choi CS, Han KY. Intravascular papillary endothelial hyperplasia (Masson tumor) of the skull: case report and literature review. J Korean Neurosurg Soc 2012;52:52-4.

25. Miller TR, Mohan S, Tondon R, Montone KT, Palmer JN, Zager $\mathrm{EL}$, et al. Intravascular papillary endothelial hyperplasia of the skull base and intracranial compartment. Clin Neurol Neurosurg 2013;115:2264-7.

How to cite this article: Mirmohammadsadeghi H, Mashhadiabbas F, Latifi F. Huge central intravascular papillary endothelial hyperplasia of the mandible: a case report and review of the literature. J Korean Assoc Oral Maxillofac Surg 2019;45:180-185. https://doi. org/10.5125/jkaoms.2019.45.4.180 